REVISTA DE DERECHO UNED, NÚM. 17, 2015

\title{
LA RESPONSABILIDAD PATRIMONIAL UNIVERSAL
}

\author{
THE UNIVERSAL ASSET LIABILITY
}

M. ${ }^{a}$ Astrid de Teresa Colina

Doctorando de la Facultad de Derecho. UNED

Resumen: Con motivo de la publicación del Real Decreto-ley 1/2015, de 27 de febrero, de mecanismo de segunda oportunidad, reducción de carga financiera y otras medidas de orden social y tal y como se pone de manifiesto en su Exposición de Motivos todavía existen muchos españoles que siguen padeciendo los efectos de la recesión, por lo que dicha norma introduce un mecanismo jurídico destinado a modular el rigor de la aplicación del artículo 1911 del Código civil para que en determinados supuestos una persona física, tenga la posibilidad de encarrilar nuevamente su vida sin tener que arrastrar indefinidamente una losa de deuda que nunca podrá satisfacer.

Evidentemente se trata de una mínima constricción en la persistencia de la afección, pero ha servido para traer a primer plano la trascendencia de la responsabilidad y la oportunidad de ponderar sus caracteres tradicionales, entre los que cabe destacar su naturaleza nuclear, universal y perenne.

Palabras claves: deuda, responsabilidad, obligación.

Abstract: Due to the publication of Royal Decree Law 1/2015 and such order as it manifests in its Explanatory Memorandum still exists many Spanish people who suffer the effects of the recession. Thus this Standard has introduced a legal mechanism to modulate the extend of the application of Article 1911 of the Civil Code so that in certain cases a person in determinated cases has the opportunity to direct

(C) UNED. Revista de Derecho UNED, núm. 17, 2015 
their life again without having to drag on indefinitely a slab of debt that can never satisfy.

Obviously this is a minimum restriction/constraint on the persistence of the condition, but it has served to bring to the fore the importance of responsability and the opportunity to weigh their traditional features, among include its nuclear, universal and perennial nature

Keywords: debt, liability, obligation

Recepción original: 15/06/2015

Aceptación original: 9/07/2015

Sumario: I. Aproximación conceptual y delimitación del concepto. I.A) Planteamiento Preliminar; I.B) Alcance terminológico. II. El principio de la responsabilidad patrimonial. III. El incumplimiento de la obligación y el artículo 1911 Código Civil. IV. La obligación de reparación. V. Conclusiones: ¿Hacia (...) una nueva responsabilidad patrimonial «universal»?

\section{APROXIMACIÓN CONCEPTUAL Y DELIMITACIÓN DEL CONCEPTO}

\section{A) Planteamiento Preliminar}

Los dos artículos o preceptos (...) que acotan jurídicamente la obligación, tanto desde el punto de vista de la deuda (artículo 1088 Código Civil -en adelante, $\mathrm{Cc}-$ : el «tener que»), como de la responsabilidad derivada del incumplimiento regulada en el artículo $1911 \mathrm{Cc}$ ('hacer frente a'), se encuentran ubicados en un lugar muy diferente dentro del Código civil ${ }^{1}$.

Esta separación física entre ambos conceptos no resulta relevante a efectos prácticos, ya que, la obligación jurídica perfecta queda integrada indisolublemente por dos elementos: la deuda y la responsabilidad $^{2}$.

${ }^{1}$ Mientras que el contenido de las obligaciones, esto es el artículo $1088 \mathrm{Cc}$, se encuentra en el Título I «De las obligaciones» y dentro de este título, encabezando el primer artículo del Capítulo I; el referido a la consecuencia o efectos del incumplimiento de dicha obligación jurídica, esto es, la responsabilidad jurídica del deudor en caso del incumplimiento de la prestación acordada con el acreedor, se encuentra en el artículo 1911 Cc, comprendido en el Título XVII «De la concurrencia y prelación de créditos», siendo igualmente el primer precepto del Capítulo I de dicho Título.

${ }^{2}$ De diferente opinión es ROCA SASTRE, Ramón M. ${ }^{\mathrm{a}}$ y PUIG BRUTAU, José. Estudios de Derecho Privado Vol. I, Aranzadi, Madrid, 2009, pág. 226, al considerar especial la sistemática empleada por el Código civil de distanciar el artículo 1088 
Sin ánimo de detenernos en el estudio de la obligación y de la deuda, pues no es el objeto de este artículo, baste añadir -para poder contraponerlo a la responsabilidad-, que la deuda implica, en esencia, la existencia de varios deberes jurídicos ${ }^{3}$ que precisan ser observados por la parte deudora de la relación obligatoria; no obstante, el deber fundamental será la realización, puntual y exacta, de la prestación contemplada en la relación obligatoria.

Sin embargo, no en todos los casos, la obligación quedará consumada con la realización de la prestación acordada, esto es, con la observancia de la conducta debida por el deudor debida, sino que pudiera suceder que dicha prestación resultara incumplida, al no observar el deudor el comportamiento a que está obligado.

del 1911, asumiendo por tanto, la escisión entre débito y responsabilidad, y siendo, por tanto, éstos considerados "no como dos elementos de la misma entidad, sino (...) como una situación jurídica autónoma de carácter instrumental respecto a la relación obligatoria».

${ }^{3}$ Siguiendo a DÍEZ-PICAZO Y PONCE DE LEÓN, Luis. Fundamentos del Derecho Civil patrimonial II, Las relaciones obligatorias, Civitas-Thomson Reuters, 6. ${ }^{\text {e }}$ ed., Madrid, 2008, pág. 141, el esquema fundamental en toda relación obligatoria es «la correlación entre un derecho de crédito y la deuda». Así las cosas, la deuda sería considerada principalmente como un deber jurídico, y entendida como la realización de una determinada conducta que comportará la prestación correspondiente de la relación obligatoria. Por tanto, no resultarán válidas aquéllas teorías que niegan la existencia de un verdadero deber jurídico del deudor y defienden la preeminencia, así como toda la atención en la responsabilidad del mismo.

Acertadamente DÍEZ-PICAZO prefiere utilizar el término "situación de deuda» frente al de «deuda», pues el primero de ellos es un concepto jurídico más completo. La «situación de deuda» quedaría definida como aquélla "porción de deberes jurídicos que pesan sobre el deudor» (se advierte que, a pesar de que en esta definición sólo se contemplan deberes, el Ordenamiento Jurídico otorga determinadas facultades a la parte deudora para proteger su situación jurídica). No obstante, resulta obligado identificar el deber principal del deudor en la relación obligatoria: la realización de la prestación acordada y por él comprometida.

En cuanto a la otra parte de la correlación anteriormente referida - «el derecho de crédito»-, sería entendida como un derecho subjetivo del acreedor que le posibilita obtener la satisfacción de la prestación acordada con el deudor (en idéntica situación que en anterior supuesto, el acreedor posee derechos, pero la norma también impone determinadas cargas al respecto). Y es que, del mismo modo que DÍEZ-PICAZO expande el término de deuda, idéntica ampliación realiza con el del crédito, definiendo éste como»un centro de unificación e imputación de facultades jurídicas». Por tanto, resulta evidente que el núcleo esencial de este derecho de crédito es la facultad de exigir la prestación acordada.

Asimismo, y como destaca la doctrina, las facultades conferidas al acreedor, como titular de un derecho de crédito, le permitirán controlar y vigilar el comportamiento de la obligación, así como conservar la capacidad económica del patrimonio del deudor a partir de mecanismos jurídicos determinados y especificados por el ordenamiento jurídico. 
Es en este momento, cuando el ordenamiento jurídico activa el mecanismo de la responsabilidad, entendida como el poder inherente al acreedor que le faculta para hacer efectivo su interés obligacional, tal cual debería haberlo materializado, motu propio, el deudor o por su equivalente pecuniario obtenido, también forzosamente, a costa de los recursos patrimoniales del obligado

\section{B) Alcance terminológico}

A partir del derecho subjetivo que el Ordenamiento le otorga, el acreedor mantendrá un poder de agresión sobre los bienes o patrimonio del deudor para intentar obtener así, la satisfacción de su pretensión incumplida. Estamos ante la denominada responsabilidad patrimonial del deudor, que podría ser definida como "un estado de sujeción, consistente en que la ley coloca los bienes del deudor frente a la acción ejecutiva del acreedor ${ }^{4} »^{5}$.

Una connotación más amplia del término responsabilidad, incluiría «todos los instrumentos compulsivos con que cuenta el acreedor tendentes a satisfacer su interés genérico ${ }^{6}$. Sin embargo, esta última definición, realiza un especial énfasis sobre los instrumentos con que cuenta el acreedor para ver satisfecho su interés, esto es, sobre el poder de agresión que recae sobre los bienes del deudor para que el

${ }^{4}$ ROCA SASTRE, Ramón M. ${ }^{a}$ y PUIG BRUTAU, José. Estudios de Derecho privado... cit., págs. 226-227. En este mismo sentido, consideran esta acción ejecutiva del acreedor como «una de las consecuencias del acto injusto de incumplimiento». Asimismo, reiteramos la opinión doctrinal de estos dos autores sobre la responsabilidad, a la que consideran como un elemento no constitutivo de la obligación, $\mathrm{y}$ "únicamente una sanción del incumplimiento y el medio de realización coactiva del derecho del acreedor»

${ }^{5}$ En términos similares CORDERO LOBATO, Encarna en BERCOVITZ RODRÍGUEZ-CANO, Rodrigo (Dtor.). Comentarios al Código Civil, Tomo IX, Tirant lo Blanch, Valencia, 2013, pág. 13057.

Como presupuestos de la responsabilidad, BLASCO GASCÓ, Francisco de Paula, en VALPUESTA FERNANDEZ, M. R. (Coord.). Derecho de obligaciones y contrato, Ed. Tirant lo Blanch, Valencia, 1994, pág. 64 considera que: (i) Se trata de una responsabilidad de carácter necesario e instrumental en relación con el incumplimiento del deudor; en caso contrario, parecería que no nos encontramos ante una relación jurídica obligatoria en sentido pleno (ii) Es una reacción del Ordenamiento Jurídico a disposición del acreedor, tal y como estipula el artículo 1101 y 1186 Cc (iii) A partir de la responsabilidad, el acreedor posee un instrumento para la realización del derecho del acreedor, in natura o por el equivalente.

${ }^{6}$ En este sentido, CAPILLA RONCERO, Francisco. La responsabilidad patrimonial universal y el fortalecimiento de la protección del crédito, Fundación universitaria de Jerez, Cádiz, 1988. 
acreedor pueda obtener la satisfacción de su obligación, aproximando a estos efectos la responsabilidad al concepto de ejecución forzosa ${ }^{7}$.

A modo de aproximación preliminar y punto de partida para analizar posteriormente los diferentes extremos implícitos en esa concepción jurídica, podríamos definir la responsabilidad patrimonial del deudor como «la sujeción de los bienes del deudor al cumplimiento coactivo de la deuda frente al poder o la facultad de agresión que se atribuye al acreedor» ${ }^{8}$. Se trataría de una «responsabilidad general» que se encontraría presente actual o potencialmente en todas las obligaciones y que entraría en funcionamiento ante el incumplimiento del deudor como un medio general de protección del derecho de crédito 9 .

\section{EL PRINCIPIO DE LA RESPONSABILIDAD PATRIMONIAL}

El principio de responsabilidad patrimonial se encuentra, de una $\mathrm{u}$ otra manera, en todas las legislaciones que conforman un Estado de

${ }^{7}$ CAPILLA RONCERO, Francisco. La responsabilidad patrimonial... cit., págs. 13 y 17, caracteriza la responsabilidad como el último medio de compulsión; mientras, la ejecución forzosa sería el medio a través del que se realizaría la agresión patrimonial.

A pesar de que la ejecución forzosa es un instrumento utilizado por la responsabilidad para hacer efectivo el interés del acreedor que no ha sido satisfecho en tiempo y forma, dicha responsabilidad, como ingrediente necesario de la obligación, no puede quedar reducida a la ejecución forzosa, pues implicaría empequeñecer injustamente el concepto.

${ }^{8}$ En términos análogos, BLASCO GASCÓ, Francisco de Paula, en VALPUESTA FERNÁNDEZ, M. R. (Coord.). Derecho de obligaciones y contratos... cit., pág. 64.

Como puede observarse en las distintas definiciones de responsabilidad aportadas por la doctrina, las notas características de este concepto jurídico son la sujeción del patrimonio del deudor, así como la facultad o poder ejercido por el acreedor para compeler patrimonialmente al deudor y ver así satisfecha su pretensión.

Igualmente, CAPILLA RONCERO, Francisco. La responsabilidad patrimonial... cit., p.92, destaca que tanto la responsabilidad patrimonial universal como la ejecución forzosa invaden la esfera de autonomía del obligado. Por ello, deberán regirse por el principio de tipicidad, por el que las agresiones a la autonomía del deudor y contra su esfera patrimonial se produce únicamente a partir de los mecanismos y supuestos previstos en las leyes.

${ }^{9}$ En este sentido, LASARTE, Carlos. Derecho de Obligaciones. Principios de Derecho Civil II, 17. a ed., Marcial Pons, Madrid, 2013, p. 208. Igualmente deberemos tener en cuenta que el ordenamiento jurídico establece medidas de protección del crédito de dos tipos: «generales» y «específicas». Así, mientras las medidas generales serán la protección que ofrece el artículo 1911 Cc a todas las obligaciones, las medidas específicas serían aquéllas que han sido pactadas convencionalmente por la autonomía de la voluntad de las partes contratantes, o aquellas previstas por la Ley para determinadas obligaciones. 
Derecho, puesto que constituye «una consecuencia natural de la obligación que ha de ser cumplida» ${ }^{10}$.

En nuestro Código civil, encuentra su manifestación en el artículo 1911 Cc, que resulta de aplicación a todas las obligaciones ${ }^{11}$, y cuyo contenido proclama que «del cumplimiento de las obligaciones responde el deudor con todos sus bienes, presentes y futuros». Nos encontramos, pues ante un ordenamiento jurídico cuya responsabilidad se caracteriza por la patrimonialidad y la universalidad ${ }^{12}$.

El artículo 1911 Cc al proclamar la patrimonialidad de la responsabilidad deroga definitivamente los vestigios históricos de un Derecho arcaico, en el que el obligado respondía con su persona e incluso con su propia vida ${ }^{13}$. Por tanto, y una vez materializada la

${ }^{10}$ Debe tenerse en cuenta que para que surja la responsabilidad deberá existir una obligación, un incumplimiento imputable al deudor, así como que dicho incumplimiento haya causado un daño (vid. en este sentido, LASARTE, Carlos. Derecho de Obligaciones... cit., págs. 211-212).

Ver MANRESA NAVARRO, José María. Comentarios al Código civil español, Tomo XII, 6. ${ }^{\text {a }}$ edición, Reus, Madrid, 1973, pág. 924 quien considera que este precepto es el que «más acusa el grado de tensión social en que se encuentra la ciencia jurídica en cada momento histórico dado», haciendo referencia así a dos aspectos fundamentales que considera propios del derecho civil moderno: el personalista y el económico.

${ }^{11}$ En principio, efectivamente, se aplicará a todas las obligaciones reguladas en nuestro Código civil; sin embargo, existirán excepciones a este principio.

${ }^{12}$ Para CAPILLA RONCERO, Francisco. La responsabilidad patrimonial... cit., pág. 9 la responsabilidad que emana del artículo 1911 Cc no sólo será patrimonial y universal, -tal y como se desprende de dicho artículo-, sino que además, se tratará de una responsabilidad general y reparadora del daño causado.

LASARTE, Carlos. Derecho de Obligaciones... cit., págs. 208-210 sistematiza la sustancia de la responsabilidad patrimonial universal en los siguientes aspectos: (i) responsabilidad general, (ii) derivada del incumplimiento, (iii) personal, como concepto éste contrapuesto a responsabilidad de bienes, (iv) exclusivamente patrimonial y (v) universal.

ROCA SASTRE, Ramón M. a y PUIG BRUTAU, José. Estudios de Derecho privado... cit., pág. 225 advierten de la diferencia entre la responsabilidad universal y la responsabilidad ilimitada. En el artículo 1911 Cc tiene cabida la responsabilidad universal, pero no ilimitada. Se deberá tener en cuenta que el deudor responderá con todos sus bienes, pero sólo en la cuantía o con los bienes suficientes para cubrir la responsabilidad.

${ }^{13}$ Resulta de gran interés, en este sentido, vid. CAPILLA RONCERO, Francisco. La responsabilidad patrimonial... cit., pág. 129. Enfatiza la evolución de la responsabilidad, partiendo de una responsabilidad sobre la persona y de carácter punitivo, que comienza a desaparecer a favor de sanciones patrimoniales también de carácter punitivo, con una responsabilidad sobre la persona de modo subsidiario. Posteriormente, esa responsabilidad personal desaparecerá totalmente subsistiendo y permaneciendo la responsabilidad patrimonial de carácter reparador.

En cualquier caso, y a partir de la proclama del artículo 1911 Cc se deroga definitivamente la responsabilidad personal que hasta el siglo XIX subsistió aunque fuera 
responsabilidad del deudor en sus bienes, desaparecerá definitivamente y en todas sus manifestaciones la responsabilidad personal o «a la persona $»^{14}$.

De este modo, el deudor responderá del incumplimiento exclusivamente con sus bienes ${ }^{15}$, pero no sólo los que mantenga en su órbita o esfera patrimonial en el momento del incumplimiento ${ }^{16}$, sino que además deberá responder «con los habidos y por haber».

de un modo residual y subsidiario. A pesar de que la Lex Poetelia instaura el sistema de responsabilidad patrimonial, no desaparece totalmente la responsabilidad personal. Así, el deudor que no señalara bienes de su patrimonio sobre los que hacer efectivo la pretensión del acreedor incumplida, o que careciera de ellos, podría ser sometido a la additio del acreedor. En el Derecho Justinianeo esta additio fue sustituida por la prisión por deudas. No obstante, esta prisión por deudas, de una u otra forma, pervivió como subsidiaria de la responsabilidad patrimonial hasta la promulgación del Código civil. En este sentido, todavía en el Proyecto de Código civil de García Goyena de 1851, en su artículo 1920, se hacía referencia al apremio personal para el incumplimiento de determinadas obligaciones.

${ }^{14}$ Expresión que prefiere CAPILLA RONCERO. Una visión diferente aporta MANRESA NAVARRO, José M. . . Comentarios... (artículo 1911 Cc) cit., pág. 928 al considerar que, a pesar de la existencia en nuestro Código civil de una responsabilidad exclusivamente patrimonial, no debería quedar derogada definitivamente la responsabilidad personal (pero no entendida ésta como prisión por deudas o el pago hasta incluso con su propia vida). Esta «responsabilidad personal» aludida por MANRESA no conllevaría excluir el carácter económico de la responsabilidad aportado por el artículo $1911 \mathrm{Cc}$, sino relegar éste a un segundo lugar «dando preeminencia al valor humano, que por sí mismo, debe constituir garantía suficiente para responsabilidad el incumplimiento de las obligaciones».

${ }^{15}$ Destacar el concepto de «bienes» aportado por MANRESA NAVARRO, José M. ${ }^{\mathrm{a}}$ Comentarios... (artículo 1911 Cc) cit., págs. 925-926 al contraponer los bienes del artículo $1911 \mathrm{Cc}$ con los del artículo $333 \mathrm{Cc}$, destacando así las diferencias existentes entre ellos. Indica que los bienes del artículo $1911 \mathrm{Cc}$ son los referidos a «las cosas que son o pueden ser objeto de apropiación por parte del hombre», por lo que el concepto de bien "no sólo se limitará a lo material, sino que comprenderá lo intelectual, en cuanto susceptible de un valor».

${ }^{16}$ Conviene en este momento destacar que no resulta de interés ni objeto de este trabajo el análisis de las diferentes causas de incumplimiento de una obligación, por parte del deudor, así como la imputación o no al mismo de dicho incumplimiento. Sin embargo, y como considera MONTES PENADÉS, Vicente, en VALPUESTA FERNÁNDEZ, M. R. (Coord.). Derecho de obligaciones y contratos... cit., págs. 171-172 "no siempre la mera omisión de la prestación o la infracción o defecto de las previsiones sobre cantidad o calidad generan las consecuencias legalmente establecidas que, en su conjunto, denominamos responsabilidad por incumplimiento». Por tanto, y sin ánimo realizar una enumeración exhaustiva, se podrían resumir los factores que deberán ser valorados para adoptar la decisión de si existe incumplimiento en sentido estricto: (i)La realización de la conducta en tiempo adecuado y pactado (ii) Ajuste de la prestación a los parámetros definidos (iii) Actividad del deudor para la realización de la prestación (iv) Eventual justificación de la omisión o del defecto de conducta por factores externos (v)Satisfacción o insatisfacción del acreedor. 
Conforme se explica autorizadamente ${ }^{17}$, los bienes a los que hace referencia el artículo 1911 Cc serían aquellos que conforman el patrimonio del deudor en el momento en el que se contrae la deuda, con independencia de que lo integren, con posterioridad, otros bienes. Sin embargo, esta afirmación posee una gran importancia, puesto que puede compendiar la convicción de que, de modo indirecto, potencial o como quiera denominarse, la responsabilidad del deudor nace desde el mismo momento en que surge la obligación ${ }^{18}$.

No obstante lo referido, es evidente que este supuesto mantiene una excepción, y es la posibilidad de ejercitar la reintegración de los bienes que han salido de la esfera patrimonial de modo censurable, sustrayéndose a la responsabilidad por incumplimiento regulada en la reiterada norma ${ }^{19}$.

Sin embargo, y a pesar de que esta responsabilidad patrimonial queda de manifiesto de forma indubitada en nuestro Código civil, no ha sido entendida doctrinalmente del mismo modo. En palabras de O'CALLAGHAN estaríamos ante una «sujeción general» del patrimonio del deudor al correcto cumplimiento de la obligación contraída, o quizá en otros términos, ante una sujeción general de los bienes presentes y futuros del deudor en caso de incumplimiento de la prestación acordada en la relación obligatoria.

Este concepto de sujeción general ha sido tradicionalmente fuente de conflictos doctrinales en cuanto a su alcance y determinación. Existe una opinión doctrinal que considera que esta sujeción general presenta similares características a las que serían propias de un dere-

${ }^{17}$ BLASCO GASCÓ, Francisco de Paula, en VALPUESTA FERNÁNDEZ, M. R. (Coord.). Derecho de obligaciones y contratos... cit., pág. 63.

${ }^{18}$ Para DÍEZ-PICAZO, Luis. Fundamentos... cit., pág. 150, la responsabilidad se hace efectiva, bien sobre los bienes que el deudor tenía cuando contrajo la obligación, bien cuando ésta deviene exigible, así como los adquiridos con posterioridad por cualquier título. En este mismo sentido, vid. LASARTE, Carlos. Derecho de Obligaciones... cit., pág. 208.

${ }^{19}$ En este sentido, debe recordarse los mecanismos de tutela preventiva del crédito, así como la acción rescisoria por fraude de acreedores (artículo $1111 \mathrm{Cc}$ ). Y es que una persona física o jurídica, en su tráfico jurídico-mercantil diario, podrá realizar adquisiciones, permutas, ventas de activos, etc., sin que ello suponga un obstáculo en relación a la denominada responsabilidad del deudor por incumplimiento. El problema radicará cuando estos actos o negocios jurídicos hayan sido manifiestamente realizados para evadir la responsabilidad patrimonial enunciada en el artículo 1911 Cc. Supuestos típicos serían aquellos negocios ruinógenos que en situaciones normales, esto es, que el deudor no debiera o tuviera necesidad de responder patrimonialmente por el incumplimiento de obligaciones, nunca habrían tenido lugar, bien por el precio estipulado para la venta -fuera del precio de mercado-, bien por la persona a quien se ha realizado la venta (familiares, amigos, etc.). 
cho real (sobre un bien), manteniendo afecto, en este caso concreto, el patrimonio del deudor. Son las denominadas teorías realistas del derecho de obligaciones, que consideraban el patrimonio del deudor como objeto de un derecho de garantía ${ }^{20}$.

Como puede entenderse, nada más lejos de la realidad que esta ficticia equiparación, ya que el deudor responderá efectivamente con todos sus bienes, sin que, por otra parte, ninguno de ellos -a excepción de la constitución de un derecho real-quede singularmente afectado al cumplimiento de sus obligaciones. La distinción con un derecho real resultará, por tanto, evidente.

La práctica procesal no acepta esta confusión de planos jurídicos, puesto que, en virtud del artículo $1911 \mathrm{Cc}$, cuando el acreedor necesita materializar judicialmente la satisfacción de su interés en la prestación incumplida deberá procederse al embargo de los bienes del deudor, actuación ésta que resulta totalmente innecesaria cuando un bien se encuentra afecto a un derecho real.

En la actualidad, esta discusión doctrinal ha quedado definitivamente zanjada al asumir, de manera pacífica, las diferencias existentes entre la situación derivada de una obligación y la surgida de un derecho real, como por ejemplo, el de hipoteca, con la sujeción de determinados bienes de un patrimonio en el supuesto de incumplimiento de la relación obligatoria garantizada a través e la constitución del nominado derecho real.

En consecuencia, y a fin de evitar confusiones, no será aconsejable el empleo del término garantía, si éste es identificado como la garantía propia e inherente a un derecho real. Por el contrario, sí podría considerarse el patrimonio del deudor como una garantía, pero de otra índole, como refuerzo del compromiso asumido por el deudor ya que la «verdadera y auténtica seguridad de los acreedores está en la capacidad económica de su deudor para hacer frente a sus obligaciones», pudiendo utilizar el término garantía en el sentido de seguridad o solvencia ${ }^{21}$.

${ }^{20}$ Así, BELTRÁN DE HEREDIA Y ONÍS, Pablo. La responsabilidad patrimonial universal, en IGLESIAS PRADA, Juan Luis. Estudios jurídicos en homenaje al profesor Aurelio Menéndez, Vol IV, Civitas, Madrid, 1996, pág. 4844 cita a Rocco y Pachioni como defensores de las teoría realistas de la obligación. Para Pachioni existía dominio pleno del deudor sobre los bienes limitado por el dominio de sus acreedores, haciendo así uso de su derecho de garantía. Por su parte, para Rocco, el acreedor mantendrá una prenda general sobre el patrimonio del deudor.

${ }^{21}$ ROCA SASTRE, Ramón M. ${ }^{a}$ y PUIG BRUTAU, José. Estudios de Derecho privado... cit., pág. 227. 
Se viene a conectar, por esta vía con la aseveración ${ }^{22}$ según la cual en el Derecho moderno, no puede hablarse de prenda o derecho de garantía sobre el patrimonio del deudor, ya que en una relación obligatoria no se crea ningún derecho real a favor del acreedor (no se genera un "derecho en los bienes, sino a los bienes»). Sólo una vez vencida la deuda, podrá hacerse efectiva la responsabilidad, ya que los bienes sobre los que recae la ejecución no forman la responsabilidad, sino la garantía ${ }^{23}$.

La conexión entre solvencia y responsabilidad resulta, por tanto, evidente quedando esta responsabilidad, reforzada a través de los mecanismos jurídicos que aporta nuestro ordenamiento jurídico, tendentes a asegurar la capacidad económica del patrimonio ${ }^{24}$. Esta idea queda subrayada por DÍEZ-PICAZO para quien esta responsabilidad por incumplimiento podría ser considerada como un derecho a la solvencia del patrimonio del deudor (o en palabras del Profesor DE CASTRO $^{25}$ como «la afección a los bienes, no de los bienes»), ya que sólo una vez que ha vencido la deuda y ésta ha sido incumplida se hace efectiva la responsabilidad (ésta, como se ha indicado en numerosas ocasiones, estará presente desde el mismo inicio de la relación obligatoria).

Sin embargo, la responsabilidad no implica en sí, única y exclusivamente la existencia de un patrimonio o de bienes que conformen el mismo, por lo que la responsabilidad, como concepto, permanecerá

En términos similares CORDERO LOBATO, Encarna en BERCOVITZ RODRÍGUEZ-CANO, Rodrigo (Dtor.). Comentarios... cit., pág. 13057 quien considera que la responsabilidad patrimonial del deudor sería una garantía en sentido amplio, pero no una afección erga omnes.

Para BELTRÁN DE HEREDIA Y ONÍS, Pablo. La responsabilidad patrimonial universal, en IGLESIAS PRADA, Juan Luis. Estudios jurídicos... cit., pág. 4845 la solvencia del deudor sería entendida como «la aptitud del patrimonio para cumplir».

${ }^{22}$ En este sentido, DE CASTRO Y BRAVO, Federico. La responsabilidad patrimonial y la acción pauliana, Revista de Derecho Privado, 1932, págs. 194-195 que considera y define el patrimonio como objeto de referencia de la coacción jurídico-civil.

${ }^{23}$ En este sentido DE CASTRO Y BRAVO, Federico. La responsabilidad patrimonial... cit., pág. 196 considera que «la responsabilidad no es otra cosa que potencia, y requiere para hacerse efectiva la garantía y es que "acompaña la responsabilidad a la deuda jurídica como sombra al cuerpo». Por tratarse de que los bienes sobre los que recae la ejecución forman la garantía del cumplimiento del acreedor, la responsabilidad es inalterable la misma a pesar de que el patrimonio aumente o disminuya.

${ }^{24}$ Ver en este sentido, BELTRÁN DE HEREDIA Y ONÍS, Pablo. La responsabilidad patrimonial universal, en IGLESIAS PRADA, Juan Luis. Estudios jurídicos... cit., pág. 4845.

${ }^{25}$ DE CASTRO Y BRAVO, Federico. La responsabilidad patrimonial... cit., pág. 196. 
inalterable frente al acreedor, con independencia de que este deudor posea bienes, o sea insolvente.

Como se ha indicado con anterioridad, el ordenamiento jurídico otorga al acreedor determinados mecanismos y acciones jurídicas que realizan la tutela del crédito, bien de modo anterior o posterior al momento de la exigibilidad de la prestación ${ }^{26}$. Dicho de otro modo, todos los mecanismos de tutela preventiva del crédito «esto es, de mantenimiento de la solvencia patrimonial del deudor no son sino manifestaciones de la responsabilidad del mismo para la hipótesis de incumplimiento de la obligación». ${ }^{27}$

Por tanto, podríamos concluir este epígrafe afirmando la importancia que el artículo $1911 \mathrm{Cc}$ posee en nuestro ordenamiento jurídico como aquél precepto que proclama la responsabilidad patrimonial como única responsabilidad del deudor por incumplimiento. Sin embargo, y a pesar de la importancia nuclear de este artículo, no queda definido ni determinado el quantum por el que el deudor deberá responder de su incumplimiento. Por tanto, podríamos decir que se fijan los bienes sobre los que recaerá la responsabilidad patrimonial, sin que se determine la cuantía de dicha responsabilidad.

\section{EL INCUMPLIMIENTO DE LA OBLIGACIÓN Y EL ARTÍCULO 1911 DEL CÓDIGO CIVIL}

El cumplimiento o ejecución de la obligación, como fundamento y objetivo principal de la relación obligatoria, implica la realización u

${ }^{26}$ Así y como resume MONTÉS PENADÉS, Vicente, en VALPUESTA FERNÁNDEZ, M. R. (Coord.). Derecho de obligaciones y contratos... cit., pág. 215 la defensa preventiva del crédito quedaría plasmada en la acción revocatoria, la acción pauliana, el vencimiento anticipado, así como las medidas judiciales de aseguramiento. La tutela represiva, por su parte implicaría la obtención vía coactiva de la prestación no realizada o realizada parcialmente. No obstante, esta prestación coactiva será realizada cuando sea posible o cuando la prestación no sea personalísima. En esos casos, ésta se convertirá en una acción de daños y perjuicios que puede ser complementaria a la acción forzosa o puede sustituirla, tal y como se estudiará más adelante.

${ }^{27}$ En este sentido, merece destacar la distinción histórica que ha arrastrado nuestro derecho acerca de la responsabilidad objetiva y la subjetiva por incumplimiento. Siguiendo a BLASCO GASCÓ, Francisco de Paula, en VALPUESTA FERNÁNDEZ, M. R. (Coord.). Derecho de obligaciones y contratos... cit., pág. 198: es la tradición histórica la que ha llevado a mantener una línea subjetivista de la responsabilidad del deudor en el Cc. Sin embargo y como correctamente sintetiza esta autor «en todo caso el fundamento de la responsabilidad del deudor se encuentra en la misma obligación, en la imperiosidad de cumplir su deber de prestación. El deudor responde porque debe, no porque ha omitido o no ha prestado la diligencia exigible». Por tanto, el principio general de responsabilidad se encontraría ínsito en la misma obligación. 
observancia, por parte del deudor, del comportamiento acordado y comprometido con el acreedor -en los términos exactamente pactados en la relación obligatoria-, con la consecuente satisfacción del interés del acreedor en su derecho de crédito a través de la referida conducta del deudor.

Sin embargo, no en todos los casos la prestación debida es cumplida en los términos exactamente acordados, esto es, en tiempo y forma $^{28}$. Se produce, entonces, el incumplimiento de la obligación, con la correspondiente frustración del derecho de crédito del acreedor y la insatisfacción de su interés.

El ordenamiento jurídico reacciona ante el acto anormal e injusto $^{29}$ que representa el incumplimiento, y activa, en ese momento, la denominada responsabilidad patrimonial universal, como un mecanismo jurídico que otorga al acreedor la facultad de dirigirse contra el patrimonio del deudor para ver satisfecha su pretensión, ahora incumplida $^{30}$ e intentando, aunque sea forzosamente, que dicha obligación resulte finalmente realizada.

No obstante, debe advertirse que, en el incumplimiento de la obligación, pueden existir causas imputables y dependientes de la voluntad del deudor (en las que pueda intervenir la plena conciencia sobre la actuación realizada -dolo-, o en las que aparece negligencia-culpa-), así como causas totalmente externas e imprevistas para el deudor (-como la fuerza mayor o el caso fortuito-) $)^{31}$. En este último su-

${ }^{28}$ Tradicionalmente se utiliza el término pago o solutio para definir el concepto de extinción del vínculo jurídico. Por ello, el Código civil, en sus artículos 1156 y siguientes, regula el pago dentro de los modos de extinción de las obligaciones. No obstante, advierte CASTÁN TOBEÑAS, José. Derecho civil... cit., pág. 235 que para los modernos civilistas el cumplimiento de las obligaciones es algo más que una forma de extinguirlas, ya que es su normal desarrollo, y por tanto, debería encuadrarse en la teoría de los efectos y no en la teoría extintiva de la obligación (vid. en este sentido BELTRÁN DE HEREDIA, Pablo . El incumplimiento de las obligaciones, Edersa, Madrid, 1990, pág.. 19).

${ }^{29} \mathrm{El}$ incumplimiento es un acto anormal e injusto, diferente del delito. No obstante, pudieran existir incumplimientos que conlleven un comportamiento fraudulento del deudor, y por tanto, ser constitutivos de delito, pero ése no será el supuesto que nos ocupe en este trabajo.

${ }^{30} \mathrm{Se}$ advierte en este momento, de la diferencia fundamental entre el poder de agresión que posee el acreedor con respecto al patrimonio del deudor, de quienes observaban en ello un derecho real del acreedor sobre el patrimonio del deudor. Una prueba de esta diferencia es que, a pesar de que en principio, el acreedor se dirigirá contra todos los bienes del deudor, será posteriormente y a través del embargo cuando se particularice el bien sobre el que el acreedor intentará realizar su pretensión.

${ }^{31}$ En este sentido CASTÁN TOBEÑAS, José. Derecho civil... cit., pág. 236 quien además clasifica el incumplimiento como propio o absoluto cuando las causas de incumplimiento afectan a la esencia de ésas y hacen imposible su realización, o como 
puesto mencionado, la responsabilidad no conllevaría, en principio, consecuencias sobre el deudor; muy diferente resulta el primer supuesto, en el que el incumplimiento dependiente de la voluntad del deudor sujeta a éste a las consecuencias y responsabilidad asociadas a dicho incumplimiento. En este epígrafe sólo nos detendremos en este tipo de incumplimiento: el imputable exclusivamente al deudor de la relación obligatoria ${ }^{32}$.

Por tanto, cuando el deudor no cumple voluntariamente la prestación acordada, será compelido a la observancia del comportamiento a que estaba comprometido, de modo que siempre que dicho incumplimiento sea imputable a su persona, el Derecho intentará, por todos los medios posibles, reparar adecuadamente, y en los términos previstos, la lesión del crédito del acreedor. Es entonces, cuando la parte acreedora acude a los Tribunales e intenta que el deudor haga efectiva la prestación acordada en la relación obligatoria. Será ante la negativa de este último cuando la responsabilidad quedará materializada de modo concreto, no sobre todos los bienes, sino sobre aquellos que permitan satisfacer su pretensión: estamos ante la ejecución forzosa, como medio o instrumento que conduce a la finalidad típica de la obligación $\mathrm{n}^{33}$.

Es preciso señalar en este momento, que el poder coactivo aplicable al deudor será realizado judicialmente a través del procedimiento de ejecución. Por ello, y en el caso de que existiera una orden judicial, al respecto, el deudor podría, en primer lugar, cumplir la misma. En caso contrario, se ejercería la coacción sobre el deudor con los medios «adecuados y suficientes» propios de un Estado de Derecho. En los ordenamientos jurídicos modernos, y en concreto, en el nuestro, el deudor no podrá, en ningún caso, ser amenazado con la provocación de un mal en su persona, personalidad, o valores intrínsecos a él mismo, así como de sus personas afines. La agresión se dirigirá exclusivamente en un principio contra los bienes de que esté en posesión el

impropio o relativo, para aquéllas que a pesar de no afectar a la esencia o fin fundamental suponen un mal cumplimiento de lo efectuado. El Código civil, en su artículo 1101 no distingue entre incumplimiento y cumplimiento defectuoso.

${ }^{32}$ Igualmente, y como indica CASTÁN TOBEÑAS, José. Derecho civil... cit., pág. 236 «deben de distinguirse las diferentes causas de incumplimiento de la obligación que afectan a ésta, y que hacen imposible su realización, así como otras, que sin afectar al vínculo ni imposibilitar la prestación, supone una defectuosidad o mal cumplimiento de lo convenido». El primer supuesto sería el denominado incumplimiento propio o absoluto, y el segundo, el impropio o relativo. No obstante, el incumplimiento que depende de la voluntad del deudor podrá ser, en este sentido, propio o impropio.

${ }^{33}$ HERNÁNDEZ-GIL, Antonio. Derecho de obligaciones... cit., págs. 33-35, teniendo en cuenta que, este autor considera o define esta ejecución como de «marcada primacía». 
obligado, de modo que el acreedor verá satisfecho su interés a expensas del patrimonio del deudor.

Por tanto, responsabilidad patrimonial por incumplimiento y ejecución forzosa son conceptos íntimamente relacionados y que se condicionan recíprocamente (la ejecución forzosa es el instrumento que dota de efectividad práctica el mandato de los títulos a los que nuestro Derecho reconoce fuerza ejecutiva) $)^{34}$.

No obstante lo anterior, y a resultas del contenido de la prestación de la obligación, se podrá distinguir entre la ejecución específica (in natura) y la genérica (por el equivalente pecuniario).

Debemos partir, entonces, de la premisa de que el ordenamiento jurídico intenta que, ante la lesión del derecho de crédito sufrida por el acreedor, éste pueda encontrarse en una situación similar a la que mantendría en el supuesto de haber cumplido el deudor en tiempo y forma su prestación ${ }^{35}$. Por ello, la ejecución específica o in natura sería la preferida por nuestro Código civil -«aunque sea por la fuerza ${ }^{36}$ - y podría definirse como la «reproducción, en la fase de actuación judicial del cumplimiento omitido» ${ }^{37}$.

Esta preferencia es motivada al tener en cuenta que la satisfacción del acreedor se produce únicamente con el pago estricto de su prestación, por lo que el acreedor sólo verá satisfecha su pretensión cuando de manera exacta se cumpla la prestación acordada (de ahí la preeminencia de la ejecución específica).

${ }^{34}$ CAPILLA RONCERO, Francisco. La responsabilidad... cit., pág. 14. En este mismo sentido, este autor (p.16) destaca que las normas generales de nuestro Ordenamiento jurídico en la ejecución forzosa se corresponden a las normas sustantivas en materia de incumplimiento de las obligaciones y la responsabilidad que de ello nace.

${ }^{35}$ Para DÍEZ-PICAZO, Luis. Fundamentos... cit., pág. 781 esta afirmación queda recogida en el artículo $1101 \mathrm{Cc}$.

${ }^{36}$ LACRUZ BERDEJO, José Luis. Elementos de Derecho Civil II. Derecho de Obligaciones. Volumen I Parte General. Teoría General del Contrato, 3. ${ }^{\text {a }}$ ed. revisada y puesta al día por Francisco RIVERO HERNÁNDEZ. Dykinson, Madrid, 2003, pág. 162. En este sentido, ver artículos 1096 del Cc, así como 669 y siguientes Cc. Salvo que exista imposibilidad, nuestro Derecho prefiere la ejecución específica. Históricamente, en Roma sólo podía ofrecer dinero en los juicios, mientras que a partir del Derecho Justinianeo cuando se distingue entre la prestación originaria y la prestación del id quod interest o indemnización de daños sufridos por el acreedor. A partir de esta última concepción se introduce la idea de refuerzo o incremento que se añade a la prestación originaria. De este modo, y como indica LACRUZ BERDEJO, podría interpretarse mejor el artículo 1096 Cc.

${ }^{37}$ En este sentido HERNÁNDEZ-GIL, Antonio. Derecho de obligaciones... cit., pág. 33, y MONTÉS PENADÉS, Vicente, en VALPUESTA FERNÁNDEZ, M. R. (Coord.). Derecho de obligaciones y contratos... cit., pág. 199. 
No obstante, y a pesar de la preferencia de la ejecución específica en nuestro ordenamiento jurídico, no ha sido así tradicionalmente, ya que este modo de ejecución quedaba íntimamente relacionado con la voluntad del deudor, pudiendo entonces, quedar la misma violentada, o incluso anulada (nemo praecise cogi potest ad factum), acompañado, además de las importantes dificultades, a efectos prácticos, de la referida ejecución ${ }^{38}$.

Sin embargo, resulta evidente que, dependiendo del tipo de obligación incumplida, se podrá ofrecer una mejor o peor solución al acreedor a partir de la ejecución forzosa específica ${ }^{39}$, existiendo un amplio

${ }^{38}$ CASTÁN TOBEÑAS, José. Derecho civil... cit., pág. 226. Debe tenerse en cuenta que, en la actualidad, existe mayor apoyo de esta ejecución forzosa específica «sobre la base del reconocimiento de más amplios poderes judiciales».

No obstante, CASTÁN TOBEÑAS, José. Derecho civil... cit., pág. 267 cita a COLIN y CAPITANT como defensores de una teoría opuesta a la tradicionalmente admitida para la ejecución forzosa específica, pues defendía en el derecho del acreedor a solicitar la ejecución forzosa específica siempre que ésta fuera posible, siendo la imposibilidad material y moral, a este respecto, cubiertas a partir de la indemnización de daños y perjuicios. En el mismo sentido se muestra ALBALADEJO.

${ }^{39}$ Ofreciendo una visión un tanto más detallada dependiendo de cada tipo de obligaciones podríamos considerar lo siguientes:

(i) En las obligaciones de dar, nos encontramos ante un supuesto fácilmente ejecutable in natura, siempre que la prestación recaiga sobre una cosa determinada, específica y que se encuentre dentro del patrimonio del deudor. En este sentido, el artículo 1096.1 Cc, expresa el derecho del acreedor a compeler al deudor a que realice la entrega de cosa determinada (debida), mientras que el artículo 701 Ley Enjuiciamiento Civil (en adelante, LEC), en términos similares, recoge que, en el supuesto de cosa mueble determinada, el tribunal pondrá al ejecutante en posesión de la cosa debida, a la vez que manifiesta que si no "pudiere ser habida la cosa», ésta se sustituirá «por una justa compensación pecuniaria, que se establecerá con arreglo a los artículos 712 y siguientes».

En el supuesto de que se trate de bienes inmuebles, deberán seguirse los preceptos 703 y 704 LEC, que en términos análogos dispone que el bien inmueble será entregado al acreedor, teniendo, además, en cuenta, las consideraciones necesarias, en el caso de que existan ocupantes en dicho inmueble. Cuando se trate de cosas genéricas, se facultará al acreedor para obtener la entrega directa de la misma al acreedor, pudiendo pedir, en todo caso, el cumplimiento a expensas del deudor (artículo $1096.2{ }^{\circ}$ Cc y 702.1 LEC) y permitiendo el embargo de sus bienes para sufragar la adquisición realizada.

(ii) En las obligaciones de hacer, mantiene poca importancia la ejecución forzosa específica, pues este tipo de obligaciones quedan vinculada estrechamente a la libertad de la persona -en este sentido, ver CASTÁN TOBEÑAS, José. Derecho civil... cit., pág. 269 y DÍEZ-PICAZO, Luis. Fundamentos... cit., pág. 779-. En el supuesto de que no se trate de derechos personalísimos se recurrirá al artículo 1098 Cc que determina que, "si el obligado a hacer alguna cosa no la hiciere, se mandará ejecutar a su costa». En este mismo sentido se muestran los artículos 705 y 711 de la LEC. Sin embargo, para los derechos personalísimos, se permitirá imponer multas de fuerte cuantía para disuadir del incumplimiento. No obstante, se realizará esta imposición de la multa a partir de un procedimiento sumario en el que las partes pueden llegar a un acuerdo 
número de obligaciones en las que, debido a su objeto (naturaleza de su objeto o prestación), será imposible cumplir de manera forzosa la prestación en los términos exactos inicialmente previstos. Y ello, con independencia de que, en la práctica jurídica, serán muchas las ocasiones en las que el acreedor no muestre un especial interés en recibir el cumplimiento exacto de su prestación y prefiera recibir una contraprestación pecuniaria como valor equivalente a la misma. El acreedor podrá exigir su prestación determinada o en su defecto, procurarse una satisfacción por el equivalente (id quod interest); surge la obligación de reparar.

\section{LA OBLIGACIÓN DE REPARACIÓN}

Como se ha indicado anteriormente, en determinadas ocasiones, y resultando imposible el cumplimiento forzoso de modo específico, se sustituye la obligación primitivamente contraída por el deudor por otra, regulada y determinada por la Ley: la obligación de reparar ${ }^{40}$.

Ante la imposibilidad de la ejecución forzosa específica, el deudor deberá responder de su incumplimiento a través de la ejecución forzosa genérica o por equivalente. Esta ejecución intentará, en principio, a partir de la patrimonialidad de las obligaciones, valorar la prestación incumplida y así reparar el daño causado al acreedor al quedar insatisfecha su pretensión. A partir de la prestación por equi-

previo (para ello, la LEC distingue la condena a imponer, dependiendo de que se trate o no de derechos personalísimos). No existiría problema, en la actualidad, en admitir que la declaración de voluntad de un deudor sea sustituido por la de la autoridad judicial, siempre que así se puede satisfacer el interés del acreedor. No obstante, este hecho no podrá tener lugar cuando la prestación incumplida y debida sea «la realización de actos materiales por parte del deudor».

(iii) Para las obligaciones de no hacer, el artículo 710 LEC viene a resolver las dudas que hasta el año 2000 planteaba el artículo 1099 Cc. A partir de dicho artículo, entonces se considera que si el condenado a no hacer alguna cosa ha quebrantado dicha obligación, será instado a que deshaga lo mal hecho, si fuera posible, además de indemnizar por los daños y perjuicios causados. "Se procederá de esta forma cuantas veces incumpla la condena y para que deshaga lo mal hecho se le intimará con la imposición de multas por cada mes que transcurra sin deshacerlo».

${ }^{40}$ Indica CAPILLA RONCERO, Francisco. La responsabilidad... cit., págs. 41-43 que esta obligación de reparar queda recogida en el artículo $1101 \mathrm{Cc}$ y de manera más explícita en el artículo $1150 \mathrm{Cc}$. Asimismo, y como indica este autor, esta obligación de reparar se trata de un fenómeno autónomo y no definido prácticamente por el legislador. En este mismo sentido, esta obligación podría ser reconducida a la idea del «deber secundario», no implicando esta sustitución la extinción del deber primario, sino la transformación de su contenido. Sin embargo, para que esta obligación de reparar surja, y como se verá con posterioridad, no sólo deberá estarse ante un incumplimiento, sino que del mismo, necesariamente deberá derivarse un «daño». 
valencia «se procura la obligada restauración del desequilibrio producido en el patrimonio del acreedor por el incumplimiento ${ }^{41}$. En todo caso, se trata de "prestar al acreedor el equilibrio de aquella utilidad que le hubiera reportado el cumplimiento de la obligación en forma específica ${ }^{42}$. En nuestro Derecho, es denominado resarcimiento de daños y perjuicios.

En este momento «muta la obligación inicialmente existente por otra distinta que tiene por finalidad reparar al acreedor el daño que se le infiere de resultas del incumplimiento ${ }^{43}$. Es decir, queda sustituido el interés inicial del acreedor por otro diferente (no se tratará de una obligación nueva, sino de la modificación de la ya existente por otra cuya finalidad resida en la reparación del daño causado ${ }^{44}$ ).

Sin embargo, es evidente que esta modificación de la prestación no otorga un derecho al deudor para que no cumpla su prestación y sustituya la misma posteriormente y de modo unilateral por el equivalente; en este mismo sentido, tampoco se permitiría que el acreedor, en caso de incumplimiento de su prestación, solicitara, de modo directo, la indemnización por los daños y perjuicios sufridos ${ }^{45}$. Este nuevo interés a satisfacer, no podrá ser elegido al arbitrio de las partes, sino que será determinado por la Ley, teniendo en cuenta, además, que siempre que dicho incumplimiento provoque un daño en el acreedor, éste deberá ser reparado.

En este mismo sentido, y teniendo en cuenta que, a pesar de que con carácter general, el daño acompaña al incumplimiento, éste, de por sí, no implicará la producción del daño. Por tanto, y teniendo en cuenta que la indemnización se devenga a partir de éste y no de aquél

${ }^{41}$ CASTÁN TOBEÑAS, José. Derecho civil... cit., pág. 276.

Como acertadamente considera CORDERO LOBATO, Encarna en BERCOVITZ RODRÍGUEZ-CANO Rodrigo (Dtor.). Comentarios... cit., pág. 13057 toda prestación por ilíquida que sea puede ser convertida en prestación pecuniaria líquida.

${ }^{42}$ CASTÁN TOBEÑAS, José. Derecho civil... cit., pág. 286.

${ }^{43}$ CAPILLA RONCERO, Francisco. La responsabilidad... cit., pág. 33

${ }^{44}$ CASTÁN TOBEÑAS, José. Derecho civil... cit., pág. 276.

Como indica LACRUZ BERDEJO, José Luis. Elementos... cit., pág. 162 el incumplimiento no modifica el contenido de la obligación, que sigue siendo la prestación debida, a pesar de que según el artículo 1150 Cc parecería ignorar, con error, dicho extremo.

Esta obligación de reparar, según CAPILLA RONCERO, Francisco. La responsabilidad patrimonial... cit., pág. 45 contendrá unos presupuestos tales como (i) la necesaria preexistencia de una obligación concreta (ii) el incumplimiento imputable a dicha obligación (iii) la existencia del daño al acreedor (iv) la necesaria relación causal entre el incumplimiento y el daño producido. Por todo ello, si no existe la concurrencia de estos presupuestos no podrá existir obligación de reparar.

${ }^{45}$ CASTÁN TOBEÑAS, José. Derecho civil... cit., pág. 277. 
deberá quedar probado la efectiva producción del daño causado por el incumplimiento ${ }^{46}$.

La frustración de interés del acreedor cuando se traduce además en un daño, debe ser reparado, sin que ello implique que aparezca una nueva obligación, por lo que la obligación primitiva e incumplida queda transformada aunque se intenta guardar y mantener la mayor cantidad de características originales posibles ${ }^{47}$.

Pudiera concluirse que, una vez determinada la imputabilidad del incumplimiento del deudor, el acreedor mantiene un derecho a la indemnidad $^{48}$. No obstante, este interés a la indemnidad no estará servido por la deuda original, sino por una deuda distinta: la obligación de reparar ${ }^{49}$.

Este resarcimiento, en nuestro Código civil, es denominado con la expresión de la indemnización de daños y perjuicios, como la consecuencia jurídica de los actos ilícitos en general y que puede proceder de causas muy diversa ${ }^{50}$. Lo que viene a significar -expresado asimismo en términos magistrales ${ }^{51}$ - que «llegado el momento de cumplir y omitido o mal realizado el cumplimiento, se ha producido un daño en

${ }^{46}$ Siguiendo a ALBALADEJO, Manuel. Derecho civil II Derecho de Obligaciones, 14. ${ }^{\mathrm{a}}$ ed. Edisofer, Madrid, 2011, págs. 203-204 deberán existir determinados presupuestos para verificar la existencia del daño en el incumplimiento. Estos serían los siguientes: " $1 .^{\circ}$ que (salvo el caso del artículo 1124 Cc) no sea obtenible la ejecución exacta de la prestación in natura, $2{ }^{\circ}$ Que exista efectivamente un perjuicio, 3. ${ }^{\circ}$ Que éste proceda de dicha inejecución, $4 .^{\circ}$ Que de ella sea responsable el deudor. De estos requisitos, el primero se constata a la vista del caso; el último se presupone, en principio; el segundo y el tercero hay que probarlos».

El Tribunal Supremo exige siempre la prueba los daños para verificar la existencia de los daños y servicios (en este sentido, vid. CASTÁN TOBEÑAS, José. Derecho civil... cit., págs. 278-279).

Como indica CASTÁN TOBEÑAS, José. Derecho civil... pág. 279 en nuestro Código civil, se trata el daño, bien en un sentido amplio -como toda lesión del derecho de crédito-, bien en un sentido estricto -como daño positivo-.

${ }^{47}$ En este sentido, CAPILLA RONCERO, Francisco. La responsabilidad... cit., pág. 43.

${ }_{48}$ CAPILLA RONCERO, Francisco. La responsabilidad... cit., pág. 38.

${ }^{49}$ Para ROCA SASTRE, Ramón María, y PUIG BRUTAU, José. Estudios de Derecho privado... cit., pág. 230: la obligación de resarcir no la entiende el autor como la "obligación secundaria que la ley hace surgir como consecuencia y para la sanción del incumplimiento de la primitiva obligación».

${ }^{50}$ CASTÁN TOBEÑAS, José. Derecho civil... cit., 276.

A diferencia del Código civil, el Código Penal distingue entre restitución y reparación de los daños y la indemnización de los perjuicios (así los artículos 101 a 104 CP).

${ }^{51}$ MONTÉS PENADÉS, Vicente, en VALPUESTA FERNÁNDEZ, M. R. (Coord.). Derecho de obligaciones y contratos... cit., pág. 199. 
el patrimonio del acreedor que debe ser reparado por el deudor en la medida que quepa imputar ese daño al mismo deudor». ${ }^{52}$

Desde luego, no cabría desmerecer la redacción del artículo 1911 Cc, achacándole la omisión de la cuantía por la que deberá responder el deudor a causa de su incumplimiento (se indica que con el deudor responderá con todos sus bienes, pero no se expresa hasta qué cuantía), ya que como es obvio dicha fijación no es de su incumbencia. Al contrario, dicha acotación de los daños resarcibles la deja atendida el legislador en el artículo $1106 \mathrm{Cc}$, cuando asegura que comprenderá «no sólo el valor de la pérdida que hayan sufrido, sino también el de la ganancia que haya dejado de obtener el acreedor (...)».

La doctrina se muestra unánime en este sentido, al considerar que la indemnización deberá resarcir los daños y pérdidas sufridos a causa del incumplimiento o del cumplimiento inexacto. En todo caso, consistirá en una suma de dinero en la que se valore lo que el acreedor perdió al no recibir la prestación en tiempo y forma (esto es, el daño emergente) al igual que aquello que dejó de ganar y habría ganado de haberse cumplido la prestación (lucro cesante) ${ }^{53}$, teniendo en cuenta que el valor económico de la contraprestación no sería lucro cesante en puridad, sino cumplimiento debido ${ }^{54}$. En este mismo sentido, esta indemnización sólo desempeñará su cometido si cuando se haga efectiva al perjudicado, el poder adquisitivo resulta suficiente para cubrir en el patrimonio de éste el poder adquisitivo que tenía cuando se valoró la cifra en que se fijó el daño causado ${ }^{55}$.

${ }^{52}$ MONTÉS PENADÉS, Vicente, en VALPUESTA FERNÁNDEZ, M. R. (Coord.). Derecho de obligaciones y contratos... cit., pág. 199.

${ }^{53}$ ALBALADEJO, Manuel. Derecho civil... cit., pág. 205. En este sentido advierte ALBALADEJO Manuel. Derecho civil... cit., pág. 209 que el daño emergente es más fácil de probar y el lucro cesante él considera lo ss en base a que si se exigiese la demostración absoluta y segura de que se iba a obtener y se frustró por el incumplimiento muchas veces no se podría probar. Por ello, ALBALADEJO presume que se habría obtenido el que hubiese sido normal a tenor de las circunstancias. Cuando se dice que este lucro hay que probarlo no se pide una prueba especial sino q se prueba a partir de dicha presunción.

${ }^{54}$ En este sentido vid. CARRASCO PERERA, Ángel. Derecho de contratos, Thomson Reuters, Navarra, 2010, pp. 1210 y 1185 quien define el lucro cesante como la ganancia neta que el acreedor deja de 'percibir como consecuencia del incumplimiento del deudor o de la resolución del contrato instada por el acreedor ante el incumplimiento del deudor. Por su parte, CARRASCO distingue entre el lucro cesante de cumplimiento y el de confianza, entendido este último como una parte del coste de oportunidad del contrato celebrado e incumplido, así como el lucro cesante derivado del daño a la indemnidad.

${ }_{55}$ ALBALADEJO, Manuel. Derecho civil... cit., pág. 209 considera que «cuando el incumplimiento que ha motivado éste produjo o hizo obtener alguna ventaja al dañado, 
Teniendo en cuenta que tal y como determina el artículo $1101 \mathrm{Cc}$, no se diferencia entre incumplimiento total o parcial, este artículo entendería el resarcimiento como un recurso subsidiario ${ }^{56}$, bien como resarcimiento total de daños y perjuicios ante un incumplimiento, bien como complemento al daño producido por un cumplimiento inexacto. No obstante, deberá contar con determinados presupuestos o requisitos tales como (i) el incumplimiento culpable de la obligación (ii) no se puede obtener el cumplimiento específico (iii) existir un daño resarcible (iv) relación causa-efecto entre el incumplimiento de la obligación y el daño sobrevenido.

No obstante lo anterior, uno de los principales problemas que surgen en el incumplimiento de la prestación resultará la determinación del daño resarcible, ya que de facto puede resultar bastante complicado determinar qué pérdidas pueden alegarse y atribuirse al incumplimiento ${ }^{57}$.

\section{CONCLUSIONES: ¿HACIA (...) UNA NUEVA RESPONSABILIDAD PATRIMONIAL «UNIVERSAL»?}

La realidad mediática y social, así como algunas resoluciones judiciales más o menos recientes ${ }^{58}$ en relación al endeudamiento familiar y a la ejecución hipotecaria han traído a un primer plano la pregunta sobre si estamos ante la reformulación o refundación del principio general de responsabilidad patrimonial universal. Es decir, si ante determinadas vicisitudes sufridas por el deudor y acaecidas a partir de una situación económica financiera concreta puede producirse un perjuicio del derecho de crédito en orden a la responsabili-

que no se habría conseguido sin aquél, ésta debe computarse, para deducir su montante del daño sufrido».

${ }^{56}$ CASTÁN TOBEÑAS, José; Derecho civil... cit., pág. 278.

${ }^{57}$ La jurisprudencia del Tribunal Supremo no tiene duda alguna en la interpretación y extensión de esta indemnización de daños y perjuicios y manifiesta que "la entidad del resarcimiento, presupuesto el evento perjudicial y la conducta sancionable, abarca a todo el menoscabo económico sufrido por el acreedor, consistente en la diferencia que existe entre la actual situación del patrimonio que recibió el agravio y la que tendría de no haberse realizado el hecho dañoso, bien por disminución efectiva del activo, bien por la ganancia perdida o frustrada, pero siempre comprendiendo en su plenitud las consecuencias del acto lesivo". (STS de 2 de abril de 1997, RJ 2327/1997).

El problema del daño resarcible es determinar qué clases de pérdidas pueden ser alegadas por el perjudicado como daño indemnizable (problema de la comprensión), y de otra, qué pérdidas están en relación causal con el incumplimiento que pueden ser atribuidas a él (problema de la extensión).

${ }^{58}$ Así por ejemplo, vid. el mediático Auto de la sección 2. ${ }^{a}$ de la Audiencia Provincial de Navarra (número 111/2010) de 17 de diciembre de 2010. 
dad patrimonial de éste o, por el contrario, el deudor debe responder, en cualquier caso, con sus bienes presentes y futuros hasta el límite de la responsabilidad contraída.

Si bien la respuesta a esta pregunta no es de fácil solución puesto que existen intereses contrapuestos, lo cierto es que con la ley en la mano, la responsabilidad patrimonial universal del deudor es el mecanismo general de protección frente al incumplimiento de las obligaciones, de modo que si se pretende atemperar o atenuar el mismo entendemos que ello debería ser únicamente ante supuestos excepcionales y siempre regulados normativamente, de modo que las reglas de juego fueran claras para las dos partes, esto es, tanto para el deudor como para el acreedor, cuya pretensión es la satisfacción del derecho de crédito.

Una excepción al principio de responsabilidad patrimonial universal $^{59}$ es la regulada en el artículo 140 de la Ley Hipotecaria (en adelante, LH) que prevé la posibilidad de limitar la responsabilidad del deudor al bien hipotecado y siempre que así se haya pactado expresa e inequívocamente en el propio negocio jurídico por voluntad de ambas partes.

No obstante lo anterior y de acuerdo a nuestro ordenamiento jurídico no resultaría defendible que una de las partes de la relación obligatoria, en este caso el deudor, decidiera unilateralmente que con la entrega del bien objeto de garantía hipotecaria el acreedor fuera satisfecho en su pretensión. Esto sería equiparar el crédito con la garantía del mismo, si bien la garantía hipotecaria será siempre accesoria al crédito al que «acompaña» y deberá seguir las vicisitudes de éste y no al revés ${ }^{60}$.

${ }^{59}$ Otras excepciones al principio de responsabilidad patrimonial universal serían (i) procesales, esto es aquéllas que excluyen trabar embargo sobre determinados bienes (artículo 605 y 606 LEC), (ii) la herencia a beneficio de inventario (artículo 1023 Cc), así como (iii) el supuesto recogido en el artículo 1807 Cc por el cual de disponerlo así el constituyente, lo inembargable sería el crédito a la renta periódica.

${ }^{60}$ A estos efectos resulta de gran interés el Fundamento Jurídico séptimo de la STS de 13 de enero de 2015 (261/2015) al invocar que el artículo 1911 Cc recoge el principio general de responsabilidad patrimonial universal por deudas, al regular que "(d) el cumplimiento de las obligaciones responde el deudor con todos sus bienes presente y futuros». Conforme al artículo $105 \mathrm{LH}$, la constitución de una hipoteca sobre un bien inmueble, por los prestatarios, no altera la responsabilidad personal ilimitada del deudor que establece el reseñado artículo 1911 Cc. En este sentido, conviene advertir que las partes no convinieron, sobre la base de lo previsto en el artículo $140 \mathrm{LH}$, una responsabilidad patrimonial limitada al importe de la hipoteca o una dación en pago. En este mismo sentido, el Fundamento Jurídico noveno alude al artículo 140 LH como una excepción a lo que dispone el artículo 105 LH de la misma Ley. 
Llegados a este punto y teniendo en cuenta que el artículo $140 \mathrm{LH}$ y la excepción en él contenida en ningún caso puede ser una norma imperativa (de hecho en el tráfico jurídico en muy raras y contadas ocasiones las partes pactan dicha limitación de la responsabilidad ${ }^{61}$ ), se antoja como una opción ante las circunstancias anteriormente referidas modular en determinados y excepcionales supuestos concretos la responsabilidad patrimonial universal a partir de leyes que prevean dicha modulación excepcional, teniendo en cuenta en todo caso el principio de irretroactividad de las normas en aras a la seguridad jurídica que en cualquier caso debe prevalecer en un Estado de Derecho.

${ }^{61}$ Esta limitación prevista en el artículo 140 LH podría implicar en la práctica un aumento por parte del acreedor en los precios en los préstamos y créditos hipotecarios como respuesta a la limitación de la responsabilidad pactada ante el incumplimiento de la obligación por parte del deudor. 